\title{
Vinorelbine Regimen
}

National Cancer Institute

\section{Source}

National Cancer Institute. Vinorelbine Regimen. NCI Thesaurus. Code C160143.

A chemotherapy regimen consisting of vinorelbine that may be used in the treatment of soft tissue and AIDS-related Kaposi sarcomas; rhabdomyosarcoma; malignant pleural mesothelioma; breast, cervical, ovarian, fallopian tube, primary peritoneal, and small cell lung cancers. 